Recebido: 04/10/2013

Aprovado: 03/09/2014

\title{
Entre o idealismo e a realidade: conflitos entre o Governo Vitor Buaiz e o Partido dos Trabalhadores, no Espírito Santo (1995- 1997)
}

Ueber José de Oliveira*

Resumo: O presente trabalho tem por objetivo analisar os conflitos verificados entre Governo Vitor Buaiz (1995-1997) e o Partido dos Trabalhadores (PT), entre os anos de 1995 e 1997, ou seja, do início da administração até a saída de Vitor Buaiz e de seu grupo do Partido, ocorrido no ano de 1997, momento que coincide com a fragmentação partidária no Espírito Santo. Durante o período, diante da necessidade de se construir uma base governista em um cenário político excessivamente fragmentado como o do Espírito Santo, o governo se movimentou no sentido de buscar apoios fora do campo da esquerda, o que levou a diversos conflitos entre o Governador e seu partido, especialmente com a bancada no Legislativo local. O desfecho desse processo foi o grande racha sofrido no interior sigla e o seu enfraquecimento nos pleitos posteriores a 1997, após uma trajetória ascendente no Estado desde a sua fundação.

Palavras-chave: Partido Político; Coalizão de governo; Política.

\begin{abstract}
This study aims to analyze the conflicts between government Vitor checked Buaiz (1995-1997) and the Workers Party (PT), between the years 1995 and 1997, ie the beginning of the administration to the exit and Vitor Buaiz his Christmas Party, which occurred in 1997, when it coincides with party fragmentation in the Holy Spirit. During the period given the need to build a governing coalition in an overly fragmented political scene as the Holy Spirit, the government moved in order to seek support outside of left field, which led to several conflicts between the Governor and his party, especially with the bench in place legislature. The outcome of this process was the great rift suffered within acronym and its weakening in subsequent elections until 1997, after an upward trajectory in the state since its foundation.

Keywords: Political Party, Coalition Government, Politics.
\end{abstract}

*Doutor em Ciências Políticas pela Universidade Federal de São Carlos (UFSCAR). Professor de História na Universidade Federal do Espírito Santo (UFES). Contato: ueberoliveira@yahoo.com.br 


\section{Aspectos introdutórios}

Quando se fala na relação entre Executivo e Legislativo, conceito chave na ciência política é o poder de agenda, que se refere à capacidade que um ator qualquer possui de determinar o conteúdo, a ordem e a velocidade de votação de matérias no Legislativo (PEREIRA, 2001). Assim, parte-se do pressuposto, com base no estudo de Pereira (2001), de que certos padrões de relação entre o Executivo e Legislativo, genericamente definidas com os termos cooptação, clientelismo, fisiologismo e outros menos lisonjeiros, podem ser apreendidos como resultado de um processo que, intencionalmente, visa dar estabilidade a um determinado sistema político, mas que resulta em um mecanismo que, na prática, pode gerar maiorias avassaladoras, por um lado, e impasses de diferentes modalidades, por outro, podendo, inclusive, a acarretar crises institucionais agudas.

Partindo dessas considerações, o propósito do presente artigo é a análise do Governo petista de Vitor Buaiz (1995-1997), focando nos conflitos verificados entre Governo e o próprio Partido dos Trabalhadores (PT), entre os anos de 1995 e 1997. Durante o período delimitado, diante da necessidade de se construir uma coalizão governista, em um cenário político excessivamente fragmentado como o do Espírito Santo, o governo se movimentou no sentido de buscar apoios fora do campo da esquerda, o que levou a diversos conflitos entre o Governador e seu partido, especialmente com a bancada no Legislativo local.

A referida fragmentação partidária, bem como os conflitos verificados entre o Governo Vitor Buaiz e o PT no Espírito Santo, ocorreram em uma conjuntura marcada por profundas transformações, tanto de ordem interna ao PT, quando em termos de sistema partidário em geral, em circunstâncias marcadas pela hegemonização do ideário neoliberal, o qual adquiriu extraordinário terreno com a ocorrência da grande crise internacional do capitalismo, verificada diante da $1^{\circ}$ crise internacional do petróleo, a partir de 1973, das baixas taxas de crescimento e dos altos índices de inflação que já se faziam presentes há alguns anos.

Os limites deste trabalho não permitem aprofundar as transformações e impactos trazidos pela adoção do modelo neoliberal nas sociedades em que foi aplicado. Para a presente análise, o importante é observar alguns aspectos da hegemonia alcançada pelo neoliberalismo enquanto ideologia que, segundo Anderson (1998: 23),

[...] alcançou êxitos num grau com o qual seus fundadores jamais sonharam, disseminando a idéia de que não há alternativas para os seus princípios, que 
todos, seja confessando ou negando, têm de adaptar-se as suas normas. Provavelmente nenhuma sabedoria convencional conseguiu um predomínio tão abrangente desde o início do século como o neoliberalismo hoje. Este fenômeno chama-se hegemonia, ainda que, naturalmente, milhões de pessoas não acreditem em suas receitas e resistam a seus regimes.

Essa hegemonia neoliberal também se expressou no comportamento de partidos e governos, mesmo daqueles que formalmente sempre se colocaram como seus opositores. Além disso, é importante considerar as profundas transformações socioeconômicas e tecnológicas verificadas no último quarto do século XX e a fragmentação do socialismo real, que também abalaram profundamente as estruturas dos partidos políticos ocidentais.

Em primeiro lugar, pode-se apontar o aumento da complexidade das sociedades ocidentais, que acarretou problemas diversos aos partidos. Segundo Pedro Ribeiro (2004, 2004; $30)$,

[...] em sua dimensão estrutural, a complexificação social significou uma crescente diferenciação funcional societária, multiplicando os interesses - cada vez mais conflitantes e complexos - presentes no seio da sociedade. Tal sociedade altamente segmentada por meio de linhas demarcatórias entrecruzadas, sobrepostas e não ajustáveis a estratificações classistas tradicionais passou a organizar-se em subsistemas específicos, em microagregações de pessoas voltadas à consecução de objetivos particularistas.

Tal fragmentação desfavoreceu especialmente aqueles partidos políticos com liames societários mais fortes, como é o caso do PT, cujas bases operárias e sindicais fracionaram-se paulatinamente em vários sistemas especializados, com interesses específicos e, por vezes, conflitantes.

No caso dos partidos do tipo catch-all ${ }^{1}$, não houve tantas dificuldades, já que sua amorfa constituição mostrou-se bem mais flexível e maleável para abrigar diferentes subsistemas ideologicamente conflitantes (RIBEIRO, 2004). Mas o aparecimento dos inúmeros subsistemas, como grupos de minorias étnicas, ecologistas, organizações não governamentais, movimentos feministas de vários tipos, e outros, impeliu as agremiações partidárias a modernizarem-se sob pena de perderem grande parte dos recursos necessários à sua sobrevivência.

\footnotetext{
${ }^{1}$ Termo consagrado por Otto Kirscheimer para designar um partido que busca conquistar um maior número possível de votos, atraindo os eleitores situados nas mais diversas posições do espectro político, mediante um discurso genérico, que evita retórica de classe.
} 
No aspecto simbólico, também se observam mudanças: a crescente complexidade social culminou com a ruptura das identidades tradicionais pautadas em estruturas agregadoras e inclusivas, como igrejas e partidos. Tais organizações se enfraqueceram frente aos novos subsistemas especializados que formam identidades mais efêmeras, "[...] na medida em que em permanente rearranjo com outras microestruturas com o fito de melhor atender a seus interesses particularistas [...]” (RIBEIRO, 2004: 31).

As mudanças trazidas pela nova ordem trouxeram muitos problemas para o partido, que se tornaram mais visíveis com a sua inserção institucional. Faltava ao PT, naquele contexto, traquejo com governos e com bancadas parlamentares cujas plasticidades foram e são, em parte, forjadas pelo novo momento institucional, marcado pelas transformações trazidas pela ideologia neoliberal. Esses são elementos muito importantes na busca de explicações para os conflitos intrapartidários, a crise do governo Vitor, seguidos do insucesso político-eleitoral no Espírito Santo nos anos posteriores a 1997.

\section{As dificuldades iniciais do governo e os principais pontos de discórdia}

A fatalidade das revoluções é que sem os exaltados é impossível fazê-las. E com eles é impossível governar.

Joaquim Nabuco

Eleito após a difícil e conturbada campanha em que polarizou com um fenômeno político, o polêmico e controvertido Cabo Camata, Vitor Buaiz chegou o momento de compor o governo

de coalizão. A partir desse momento, várias dificuldades já se apresentaram. No que tange a Assembléia Legislativa, dos trinta deputados eleitos, apenas 4 eram do PT, sendo apenas um componente do grupo do governador recém-eleito, no caso Juca Alves, da Unidade na Luta. Dois eram da Articulação do B (José Baiôco e Cláudio Vereza), além de Brice Bragato, da Força Socialista (a tabela 2, da página seguinte, mostra o desenho interno do Partido dos Trabalhadores, com suas principais tendências).

Tabela 1: Partidos e representação na Assembléia Legislativa em 1995.

\begin{tabular}{lc}
\hline Partidos & Vagas por partido \\
\hline PT, PDT, PMDB, PSDB e PPB & 4 \\
\hline & \\
(PPGHIS/UnB) №. 25, Brasília, Ago- Dez 2015 ISSN 2316-1191
\end{tabular}




\begin{tabular}{lcc}
\hline PTB, PSB & 3 & 20,0 \\
\hline PFL & 2 & 6,7 \\
\hline PL, PMN & 1 & 6,7 \\
\hline Total & 30 & 100 \\
\hline
\end{tabular}

Fonte: Elaboração própria a partir dos dados do TRE-ES.

As tabelas 1 acima e a 3, logo abaixo, mostram o grau de fragmentação da nova Assembléia Legislativa: cinco partidos completamente díspares ideologicamente representavam $66,7 \%$ da casa. Os outros 33,7\% do Legislativo estavam nas mãos de outros três partidos. Se considerarmos a aliança PT/PSB/PC do B, foram eleitos seis deputados (20\%). Portanto, a base oficial do governo estava muito longe de representar uma boa sustentação. Repetiu-se assim, no legislativo estadual de 1995, a fragmentação partidária já assinalada no pleito de 1990, fato que levou a muitas dificuldades para a composição de um governo de coalizão, ao mesmo tempo em que o mesmo se tornou cada vez mais necessário.

Tabela 2 - Principais Tendências do Partido dos Trabalhadores e seus principais representantes no Espírito Santo, em meados da década de $1990 .^{2}$

\begin{tabular}{|c|c|c|c|c|c|}
\hline \multicolumn{6}{|c|}{ Esquerda $\leftarrow$ Centro $\rightarrow$ Direita } \\
\hline \multicolumn{4}{|c|}{ TENDÊNCIAS MINORITÁRIAS } & \multicolumn{2}{|c|}{ ARTICULAÇÃO DOS 113} \\
\hline O Trabalho & $\begin{array}{l}\text { Força Socialista } \\
\text { (FS) }\end{array}$ & $\begin{array}{c}\text { Democracia } \\
\text { Socialista (DS) }\end{array}$ & & $\begin{array}{l}\text { Articulação de } \\
\text { esquerda }\end{array}$ & Unidade na Luta \\
\hline $\begin{array}{l}\text { Paulo Vinha } \\
\text { Luciano } \\
\text { Avelar }\end{array}$ & $\begin{array}{l}\text { Brice Bragato } \\
\text { Robson Neves } \\
\text { (antes de 1995) } \\
\text { Lúcio Faller } \\
\text { Eliezer Tavares } \\
\text { Rita Lima } \\
\text { Gilberto A. dos } \\
\text { Santos }\end{array}$ & $\begin{array}{l}\text { Otaviano de } \\
\text { Carvalho } \\
\text { Carlos Lobo } \\
\text { Arthur Rangel } \\
\text { Viana }\end{array}$ & $\begin{array}{l}\text { Aloísio Kröhling } \\
\text { Helder Salomão } \\
\text { Pedro Bussinger }\end{array}$ & $\begin{array}{l}\text { Cláudio vereza } \\
\text { Iriny Lopes } \\
\text { João Carlos Coser } \\
\text { José Octávio Baiôco } \\
\text { Magno Pires da Silva } \\
\text { Silvio Ramos } \\
\text { Terezinha Cravo } \\
\text { Dudé }\end{array}$ & $\begin{array}{l}\text { Perly Cipriano } \\
\text { Vitor Buiaz } \\
\text { Rogério Medeiros } \\
\text { Robson Neves (a } \\
\text { partir de 1995) } \\
\text { Tarcisio Vargas } \\
\text { Maria José Machado } \\
\text { Juca Alves }\end{array}$ \\
\hline \multicolumn{4}{|c|}{ Tendências minoritárias } & \multicolumn{2}{|c|}{ Campo Majoritário* } \\
\hline
\end{tabular}

Fonte: Elaboração própria.

Tabela 3: Coligações e representação na Assembléia Legislativa em $1995^{3}$

\begin{tabular}{lll}
\hline Coligações & Vagas \\
\hline
\end{tabular}

${ }^{2}$ O agrupamento que na década de 1980 se reuniu na tendência Unidade na Luta, também conhecida como Articulação do A, foi majoritária da fundação até o ano de 1997, quando passa a ser majoritária a Articulação do B, ou Articulação de Esquerda, depois que Iriny Lopes venceu as eleições internas para a Presidência. Na mesma época, nota-se a saída do PT de boa parte dos membros da Unidade na Luta, inclusive do Governador Vitor Buaiz, seu principal representante. A partir de 2002, há um novo reordenamento e o Diretório Regional passa a ser ocupado de forma importante pela Articulação de Esquerda, pelo grupo dos Independentes e também pela Alternativa Socialista (AS), tendência recentemente fundada pelo atual Prefeito de Vitória João Carlos Coser por ocasião das divergências com a deputada Iriny Lopes, acerca dos rumos do Partido em compor ou não a coalizão do Governo Paulo Hartung.

${ }^{3}$ Fonte: Elaboração própria a partir dos dados do TRE-ES. 


\begin{tabular}{ccc}
\hline PDT/PTB & 8 & 26,7 \\
\hline PPR/PFL/PP & 6 & 20,0 \\
\hline PT/PSB/PC do B & 6 & 20,0 \\
\hline PSDB & 4 & 13,3 \\
\hline PMDB & 4 & 13,3 \\
\hline PSC/PL/PPS/PMN/PRP & 2 & 6,7 \\
\hline Total & 30 & 100,0
\end{tabular}

No Encontro do Diretório Regional do Partido dos Trabalhadores, realizado na Universidade Federal do Espírito Santo no dia 04 de junho de 1994, Rogério Medeiros, um dos mais importantes assessores de Vitor Buaiz, que no decorrer do Governo ocupou a Casa Civil e a Secretaria da Fazenda, explicitou as dificuldades enfrentadas desde o início do mandato no que diz respeito à formação de uma coalizão:

A governabilidade estabelecida a partir de conversas com os partidos políticos para formar o Secretariado de Governo, foi se constituindo numa nova forma de convivência. A maioria dos Deputados (80\%) são municipalistas, não querem enfrentar o governo, estão observando o movimento com perspectivas nas eleições/96 [...] Há um grupo de Deputados compostos por Ferraço, Adelson, Durão e Jorge Anders que querem eleger 30 projetos municipais. O grupo corre em campo próprio. Paulo Hartung busca fazer um caminho próprio, aliando-se a Ferracinho chamado campo progressista com 7/8 Deputados como sustentação [...] O PT está fora de qualquer proposta e não há aproximação e corre em campo próprio, formando seus quadros [...]. Vasco Alves assumiu o PMDB como um bloco próprio alijando outras forças do partido no processo, não dá para saber como ficará o PMDB nas mãos do Vasco. Nas SEFA, 80\% dos fiscais estão na área e/ou esquema de corrupção [...] A retração de mercado resulta em queda de arrecadação [...] Não há perspectivas de melhoria acentuada na receita. A receita não consegue acompanhar o crescimento das despesas.

Além da questão política, o novo Governador assumiu já tendo que administrar graves problemas financeiros que redundavam em sistemáticos atrasos na folha de pagamento do funcionalismo, herança do Governo Albuíno Azeredo (1991-1994). Para agravar ainda mais a situação, Vitor Buaiz fez aquilo que ele mesmo considera o grande erro da sua gestão enquanto governador, ou seja, conceder, em maio de 1995, aumento ao funcionalismo público de 25, 34\%. Segundo Buaiz: "Nosso governo tomou uma atitude equivocada, ao dar reajuste de 25\% para o funcionalismo. Nem mesmo o movimento sindical entendeu as mudanças que estavam ocorrendo e continuaram pressionando o governo [...]".

Não é outra opinião a de Perly Cipriano, outro importante nome do governo:

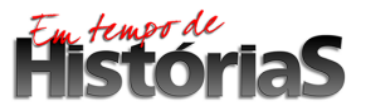


[...] acho que o maior erro do governo Vitor, que foram os $25 \%$ de aumento para os servidores, sem haver grandes demandas da sociedade dar uma aumento de $25 \%$. Quando estabilizou a moeda, $56 \%$ era uma quantidade de dinheiro astronômica e na votação do secretariado do Vitor, teve dois votos contrários a isso, um é de uma pessoa do PSDB, Ricardo Santos e outro era o meu, dois votos contrários, todo o secretariado achava que poderia dar, porque a tradição nossa era a luta no meio do movimento popular, então dar aumento de salário é uma coisa boa, não é? Deu o aumento, só que quando tinha uma inflação galopante, você podia prometer $50 \%$ de aumento, porque quando você pagasse o aumento, você pegava aquele dinheiro, deixava depositado uma semana em algum lugar, só com os juros você pagava aquela folha. Mas quando houve a estabilização, $25 \%$ a cada quatro meses era uma folha de pagamento pra trás.

O grande problema é que o PT apostou suas fichas no fracasso do Plano Real. Nesse aspecto, a Direção Nacional teve grande responsabilidade, ao não dar assistência necessária ao novo governo. Segundo Rogério Medeiros,

[...] depois quando foi dessa pressão para o Vitor dar os $25 \%$ de aumento, que foi o grande erro do Governo do Vitor, eles levaram o Vitor lá para Brasília e estava sendo estabelecido o Real, depois foram para São Paulo e aí fizeram uma reunião dizendo que o Vitor não entrasse nessa do Real que o Real era um engodo [...], não sei o que, e aí o Vitor ficou lá dois ou três dias, o pessoal daqui, eu também fiquei, e aí veio o Senador Mercadante, como grande economista que diz que é, e essa posição não haveria nada, que a inflação ia continuar.

No decorrer do ano de 1995, o Governo tomou várias medidas visando cortar gastos e aumentar a arrecadação. Mas as iniciativas não surtiram o efeito esperado, a dívida pública foi aumentando e a folha de pagamentos acumulando. Dessa forma, segundo Pereira (2004, p. 140),

[...] o governador entendeu que deveria tomar medidas drásticas para resolver a situação. No final do ano de 1995, foram enviadas à Assembléia Legislativa várias matérias, cujo objetivo era diminuir os gastos com servidores públicos. Até então, o governador não havia submetido ao Parlamento qualquer matéria mais importante e a bancada da situação, composta por deputados de diferentes origens, não havia sido realmente testada.

Além disso, ainda no ano de 1995, várias mensagens polêmicas foram enviadas à Assembléia, causando os primeiros grandes conflitos entre a bancada petista e o governo Vitor Buaiz. Dentre elas, destaca-se a que previa a venda das ações da Espírito Santo Centrais Elétricas S/A (Escelsa): a bancada, contrariando as recomendações da executiva estadual do partido e do governo, votou de forma contrária a ela. Outra questão que causou muita polêmica foi a do programa de incentivos do governo às empresas de importação e exportação por ocasião da renovação do Fundo de Desenvolvimento de Atividades Portuárias (FUNDAP).

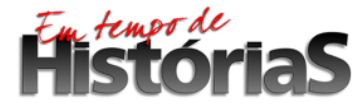


O ano de 1996 foi extremamente complicado para o Estado. Para piorar a sua já abalada situação financeira, entrou em vigor, no dia 13 de setembro, a Lei Kandir, que isentava do pagamento de ICMS os produtos e serviços destinados à exportação. Essa lei, ao interferir em uma das principais fontes de arrecadação de tributo do estado, prejudicou ainda mais o governo no que diz respeito ao equilíbrio das contas públicas, o que gerava ainda mais atrasos das folhas de pagamento e, consequentemente, mais descontentamento do funcionalismo público e conflitos com os sindicatos.

Essa situação veio a piorar no decorrer do ano de 1996 com o envio à Assembléia Legislativa do Projeto de Privatização de Empresas Públicas, entre as quais o Banco do Estado do Espírito Santo (BANESTES), além da Companhia Espírito Santense de Saneamento (CESAN). Foi feito um documento, intitulado Alerta aos Petistas, divulgado em 26 de outubro de 1996 e assinado por várias lideranças do partido, as quais, em tom de denúncia, afirmavam o seguinte:

O Governo do Espírito Santo, conduzido pelo Governador Vitor Buaiz, está levando o Partido dos Trabalhadores a viver perante a opinião pública um grave desgaste político e uma acirrada disputa interna, porque desrespeitando resoluções partidárias e descumprindo o programa democrático e popular, têm provocado junto aos movimentos sociais, sindicais, servidores públicos e formadores de opinião o descrédito político e o desprestígio da proposta do Modo Petista de Governar.

No mesmo ano de 1996, as dissensões internas do PT, já críticas, foram potencializadas pela agenda assumida pelo poder executivo. No dia 08 de setembro, em plena campanha eleitoral nos municípios, o governador do estado, junto com o presidente Estadual do PT, e à revelia dos órgãos de direção partidária, anunciou pela imprensa que o governo só entraria em campanhas nos municípios cujos interessados fossem membros da base de sustentação na Assembléia Legislativa. Na avaliação de importantes membros do PT, inclusive da bancada na Assembléia, com exceção de Juca Alves, esse ato significou uma afronta que desqualificava o partido. Denunciavam então que, em muitos municípios, a posição do governo contribuiu para a vitória de adversários do partido:

Ação do governo proporcionou a vitória de adversários históricos do PT, com a inauguração de obras, prestação de serviços, presença de membros do Governo nos palanques dos adversários, favorecendo com créditos políticos aos adversários do PT as poucas realizações do Governo Estadual, como o ocorrido nos municípios de Viana, Barra de São Francisco, Linhares, Jerônimo Monteiro, Nova Venécia, São Mateus, Jaguaré, Vitória, Vila Pavão, Colatina, entre outros.

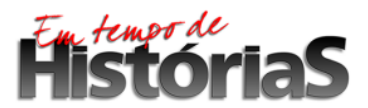


Por conta dos desacertos no lançamento de candidatos nos municípios, o resultado das eleições locais de 1996 não foi dos melhores para o PT, pois elegeu prefeitos em apenas três municípios: Brejetuba, Conceição da Barra e Fundão. Apesar de ter obtido um resultado melhor do que no pleito anterior (em 1992 venceu em apenas um município), o resultado não pôde ser considerado bom, principalmente por se tratar do partido que estava ocupando o governo do estado. Além disso, os municípios nos quais o PT obteve êxito em 1996 não estavam entre os mais importantes. O resultado contrastou completamente com aquele obtido pelo PT no plano nacional, quando conquistou 111 (cento e onze) prefeituras, dobrando a quantidade do pleito de 1992, quando conseguiu eleger 54 (cinqüenta e quatro) chefes municipais em todo o país. A tabela abaixo mostra o desempenho do Partido em pleitos majoritários e municipais, em comparação com agremiações congêneres. Pelo gráfico, é possível perceber que o subsistema eleitoral do Espírito Santo funciona com altíssimo grau de incerteza por conta das oscilações dos desempenhos partidários.

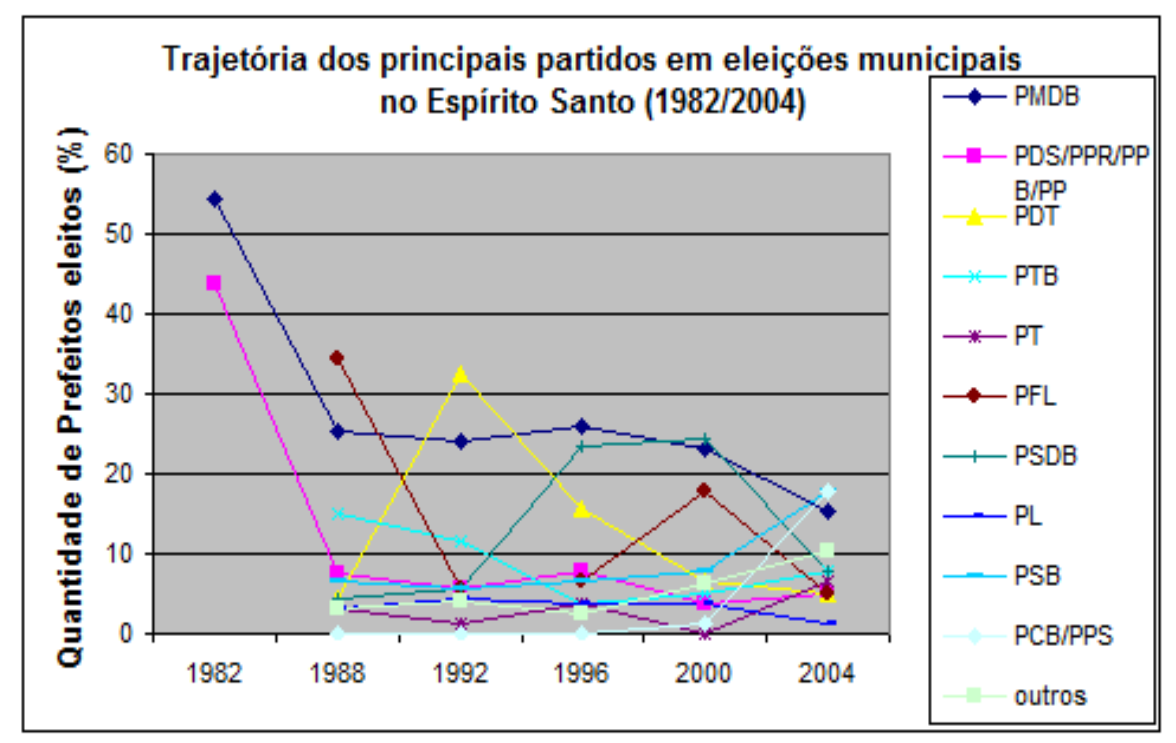

Fonte: Elaboração própria a partir dos dados do TRE-ES.

É importante registrar que o PMDB foi o partido que mais conquistou municípios no ano de 1996 no Espírito Santo, perfazendo um total de 20 prefeituras num total de 77, seguido do PSDB, que conquistou 18 e do PDT com 12 municípios.

Tabela 4 - Número de Prefeitos eleitos no ES, por partido - 1996 


\begin{tabular}{ccc}
\hline Partido & $\mathrm{N}^{\circ}$ & $\%$ \\
\hline PMDB & 20 & 25,97 \\
\hline PSDB & 18 & 23,37 \\
\hline PDT & 12 & 15,58 \\
\hline PPB & 06 & 7,79 \\
\hline PFL & 05 & 6,49 \\
\hline PSB & 05 & 6,49 \\
\hline PTB & 03 & 3,89 \\
\hline PL & 03 & 3,89 \\
\hline PT & 03 & 3,89 \\
\hline PSD & 01 & 1,29 \\
\hline PMN & 01 & 1,29 \\
\hline Total & 77 & 100
\end{tabular}

Fonte: TRE-ES - Elaboração própria

Ainda no que diz respeito à nova agenda assumida pelo executivo estadual, Pereira (2004) aponta o seguinte:

[...] a guinada em termos de proposta de administração pública, consubstanciada em um novo conjunto de matérias, enviadas a ALES na segunda metade do ano. Destacam-se: a criação de um órgão responsável por reunir as empresas públicas mais rentáveis do Estado (Agência para o Desenvolvimento em Rede do Espírito Santo - ADERES); liberdade ao Executivo para promover privatizações ou concessões de serviços públicos por decreto e aumento da contribuição dos servidores ao Instituto de Previdência e Assistência Jerônimo Monteiro (IPAJM).

No mesmo documento, Alerta aos Petistas, reconhecia-se a crise do Estado Brasileiro, decorrente, dentre outros fatores, de sucessivas políticas econômicas que centralizaram os recursos políticos nas mãos do governo federal. Apontava-se também que a então política de estabilidade monetária levada a cabo pelo Presidente Fernando Henrique Cardoso, com altas taxas de juros combinadas com a recessão econômica e o desemprego, agravou a situação das finanças públicas em diversos estados, e uma das maiores vítimas era o Espírito Santo. Além disso, o documento fazia críticas ao Programa de Demissão Voluntária (PDV); a contratos com a Caixa Econômica Federal; e à já citada política de renúncias físcais do governo do estado. E completava denunciando a suposta adesão do governador Vitor Buaiz à política de FHC, que, segundo o documento, estava expressa em entrevista à "Revista Veja, de 23 de outubro de 1996, [na qual declarava] o seu apoio ao projeto da reeleição e às reformas do Governo Federal, confrontando-se a um só tempo publicamente com as posições da bancada federal [...] e com as posições do Diretório Nacional do PT”. 
O documento citado assinalava ainda que o governo, com suas posições, afastava-se do programa democrático e popular, dos movimentos sociais, inibindo o processo de democratização do Estado, e se aproximava cada vez mais de setores empresariais que, "no Espírito Santo, sempre privatizaram os recursos públicos, através de instrumentos como o FUNDAP, caso do SINDIEX (Sindicato dos Importadores e Exportadores Capixabas)”.

$\mathrm{Na}$ prática, sacramentou-se o rompimento dos deputados do PT e de uma porção significativa do próprio Partido com o Governo. Segundo Pereira (2004, p. 141), diante desse quadro de crise,

[...] Buaiz iniciou negociações para ampliar a participação de lideranças políticas na sua administração, tendo em vista, inclusive, melhor articulação em Brasília. A maior parte destes, porém, não assumiu compromissos. O desgaste do governo era muito alto e permaneceria assim deste jeito até o final do mandato

Ainda nos últimos meses de 1996, o governo retomou medidas voltadas para cortes de gastos com servidores, a aprovação da ADERES e a autorização para a tomada de um empréstimo do governo federal cujo objetivo era liquidar as folhas de pagamentos em atraso. Naquele momento, o Legislativo estadual já havia se dividido em três agrupamentos: um governista, um independente e um de oposição, no qual se inseriam três dos quatro parlamentares petistas (PEREIRA, 2004).

No início de 1997 a coisa viria a piorar ainda mais, com a formação de uma coalizão de governo contando, segundo acusações do PT, com a indicação de dois secretários de Estado e com a eleição para a presidência da Assembléia Legislativa do principal líder do grupo dos independentes, José Carlos Gratz (PFL) (PEREIRA, 2004). Essa aliança foi alvo de mais um sem número de críticas por parte do partido.

Diante de todos esses problemas, os conflitos envolvendo o Governo e o Partido dos Trabalhadores aumentaram significativamente, culminando com a convocação de Vitor à Executiva Nacional para se explicar. Isso ficou claro em um documento divulgado no mês de julho de 1997, em que o Partido dos Trabalhadores, por sua instância máxima estadual, deliberava que: o governo procedesse à imediata revisão de sua base de sustentação na Assembléia Legislativa (artigo I); e que instituísse de fato o controle social sobre o Estado, efetivando sua real governabilidade, com a participação dos movimentos sociais, através do alargamento dos mecanismos de participação popular (artigo II). Deliberou-se também que o 
Governo deveria extinguir o Conselho de Estado e que fossem implementadas políticas tais como Orçamento Participativo (artigo VII).

\section{Idealismo e realidade: as incompatibilidades entre o Governo Vitor e o PT}

Foge dos objetivos deste trabalho fazer juízo de valor acerca de qual dos dois lados estava com a razão. Endossamos a idéia de que o importante é ter a compreensão de que havia uma incompatibilidade ideológica, entre a Unidade na Luta e as tendências minoritárias, de modo a tornar inviável a convivência no mesmo partido. Os princípios ideológicos que norteavam as visões de mundo dos dois agrupamentos eram completamente divergentes. Isso ficou muito evidente no depoimento de Vitor Buaiz quando fala acerca da formação de alianças, composição de governos e dos fatores que provocaram as crises entre o seu governo e o PT:

[...] a partir do momento que nós havíamos feito uma campanha eleitoral com o apoio do PSDB, estava implícito que dentro da equipe teríamos secretários tucanos Isso foi feito durante o processo e não teve nenhuma dissidência interna em relação aos partidos que participavam, não só o apoio do PSDB, como também o PC do B, PCB, na época nem sei se tinha o PPS já? Eu acho que não? Então houve uma ampla composição, talvez seja a primeira composição políticoeleitoral que o PT fez com o PSDB no Brasil e que deu certo[...]. Eu não poderia deixar de ter o apoio de um deputado que não fosse do partido se esse deputado tava concordando com todos os projetos políticos do governo. A bancada não queria que desse apoio a determinado parlamentar que tinha uma atuação política no município do interior do Estado. Mas ele é de direita... Governo é governo e partido é partido e eles não conseguiam separar isso. Eles queriam que o governador fosse seguir a cartilha do partido, enquanto que eu disse logo no primeiro ano de governo: eu não sou governador do PT, eu sou governador do estado do Espírito Santo.

Nota-se que Vitor Buaiz enxerga a democracia como de fato representativa e de partidos, na qual cada força política pode e deve participar da composição de governos, desde que tenha uma afinidade mínima e independente de aspectos ideológicos.

Sem entrar no mérito da questão quanto às tendências existentes no interior do PT e aos conflitos subjacentes a elas, Vitor Buaiz não as reconhecia como algo benéfico para a vida do partido:

Naquela ocasião tinha a Articulação, depois se transformou na Articulação do B, que é uma dissidência da Articulação, e tinha o João Carlos Coser e a Iriny como as lideranças. Tinha... não lembro mais porque eu deletei isso da minha memória...(risos). Tinha a do Otaviano, a $D S$, [...], que era mais chegada, a Força Socialista, essa era mais sectária, da Brice Bragatto. Tanto naquela época

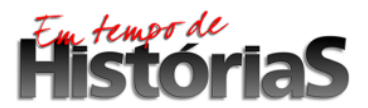


e depois quando eu fui governador e prefeito, continuaram fazendo oposição ao nosso governo [...] se discutia ideologia e aí para a comunidade aquele debate não era interessante, podia ser interessante [...] para o partido.

Diante de todo esse quadro de conflitos e a despeito das tentativas de reconciliação, um fato veio a corroborar com a complicada relação Vitor/PT: a Articulação do B, com Iriny Lopes à frente e contando com os apoios da Democracia Socialista (DS), Força Socialista, e de outros agrupamentos opositores à Unidade na Luta (tendência do Governador Vitor Buaiz), venceu a disputa interna pela direção do partido. A situação, que era complicada para Vitor, ficou insustentável, levando ao seu pedido de desligamento da sigla em agosto de 1997, transferindo-se para o Partido Verde (PV).

\section{Considerações finais}

Em 1998, já filiado ao Partido Verde (PV) e com baixa popularidade devido a não resolução dos principais problemas que abatiam o Estado, especialmente na área econômica, Vitor Buaiz resolveu não se candidatar à reeleição, retirando-se definitivamente da vida política.

A saída de Buaiz do PT redundou na debandada de importantes lideranças do partido. Cerca de cinqüenta membros pediram desligamento, dentre os quais se destacavam: o Secretário de Educação, Robson Neves; o de Transportes, Fernando Bettarello; o Diretor do Banestes, Waldir Toniato e o presidente da CESAN, Cláudio Machado, além de Rogério Medeiros, que já havia deixado o partido. De acordo com Scherer (2005, p. 91), o PT, na ocasião, "perdeu cerca de $40 \%$ de seus membros".

Depois de 1997, o PT se fragilizou muito eleitoralmente. Em 1998, teve um desempenho muito ruim: além de não ter conseguido lançar candidatos nas eleições majoritárias, elegeu apenas 1 (um) deputado estadual e 1 (um) federal. Em 2000, nas eleições locais, teve um rendimento ainda pior, não conseguindo eleger nenhum prefeito.

O ano de 2002 marca a trajetória político-eleitoral do PT pela chegada de Luiz Ignácio Lula da Silva ao cargo Presidente da República do Brasil. Para o PT capixaba, o ano é também muito representativo: foi o princípio do recomeço no aspecto eleitoral. Embora ainda não tivesse reunido condições de lançar candidatura própria ao governo, obteve bons resultados nas eleições proporcionais, elegendo 4 (quatro) deputados estaduais e 1 (um) federal, além de ter obtido uma boa votação para o Senado (584.666 votos com João Coser), mesmo que o seu candidato não

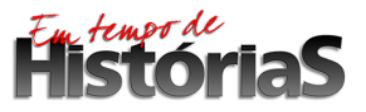


tenha sido eleito. Tudo isso ocorreu depois de sistemáticos fracassos eleitorais verificados e 1998 e 2000. Mas esse novo momento do partido iniciado a partir de 2002, é tema para outro artigo.

\section{Referências Bibliográficas}

ANDERSON, Perry. Balanço do neoliberalismo. In: SADER, E.; GENTILI, P. (Orgs). Pós Neoliberalismo: as políticas sociais e o Estado democrático. Rio de Janeiro: Paz \& Terra, 1995. p. 9-23.

BRAGATO, Brice. Desempenho político-eleitoral do Partido dos Trabalhadores, no Espírito Santo, nas eleições de 1982 a 2002. 2008. Entrevista concedida a Ueber José de Oliveira, Vitória, 29 abr. 2008.

BUAIZ, Vitor. Desempenho político-eleitoral do Partido dos Trabalhadores, no Espírito Santo, nas eleições de 1982 a 2002. 2008. Entrevista concedida a Ueber José de Oliveira, Vitória, 14 abr. e 19 mai. 2008.

BUAIZ, Vitor. O Governo Vitor Buaiz. Revista Essa. Entrevista concedida a Nilo De Mingo, Vitória, 19 abr. 2006.

CAMATA. Djair. Meu grupo é o povão. Revista Capixaba Agora, Vitória, p.05 - 15 Dez. 1997. Ano I - Número 1. Entrevista concedida a Tinoco dos Anjos, Milson Henriques e Alexandre Caetano.

KECK, Margareth. PT - a lógica da diferença. O Partido dos Trabalhadores na construção da democracia brasileira. São Paulo: Âtica, 1991.

MEDEIROS, Rogério Sarlo de. Desempenho político-eleitoral do Partido dos Trabalhadores, no Espírito Santo, nas eleições de 1982 a 2002. 2008. Entrevista concedida a Ueber José de Oliveira, Vitória, 10 abr. 2008

MENEGUELO, Raquel. PT - A formação de um partido (1979-1982). São Paulo: Paz \& Terra, 1989.

PARTIDO DOS TRABALHADORES. Alerta aos Petistas, Vitória, p. 01, 26 out. 1996.

PARTIDO DOS TRABALHADORES. Encontro Diretório Regional do PT, ampliado. Vitória, p. 2-3, 04 jun. 1994.

PEREIRA, André Ricardo Valle Vasco. Por baixo dos panos: governos e assembléias no Brasil Republicano. 2004. 239 f. Tese (doutorado em Ciência Política) - Instituto Universitário de Pesquisas do Rio de Janeiro, Rio de Janeiro, 2004.

PEREIRA, André Ricardo Vale Vasco. Coalizões de governo no presidencialismo. Dimensões Revista de História da Ufes, Vitória, n. 12, 2001.

PINTO, Carolina Julia. Partido dos trabalhadores 20 anos: a institucionalização da rebeldia. Trajetória no Espírito Santo. Formação do PT na cidade de Viana: 2001. 152 f. Monografia (Graduação em História) - Departamento de História, Universidade Federal do Espírito Santo, Vitória, 2001.

RIBEIRO, Pedro José Floriano. Campanhas eleitorais em sociedades midiáticas: articulando e revisando conceitos. Sociol. Polít., Curitiba,n. 22, p. 25-43. 2004.

SCHERER, Canício. Entre a utopia e a Realidade: tensões e conflitos entre PT e Vitor Buaiz (1995-1998), 2005. 159 f. Dissertação (Mestrado em História) - Programa de Pós-Graduação em História Social das Relações Políticas, Universidade Federal do Espírito Santo, Vitória, 2005. 